\title{
Mudança climática e seus efeitos na cultura da mandioca
}

\author{
Luana F. Gabriel ${ }^{1}$, Nereu A. Streck ${ }^{2}$, Lilian O. Uhlmann², \\ Michel R. da Silva ${ }^{4}$ \& Stefanía D. da Silva ${ }^{5}$ \\ ${ }^{1}$ Departamento de Fitotecnia/UFSM, Santa Maria, RS. E-mail: luana2fernandes@gmail.com \\ ${ }^{2}$ Departamento de Fitotecnia/UFSM, Santa Maria, RS. E-mail: nstreck1@smail.ufsm.br (Autor correspondente) \\ ${ }_{3}^{3}$ Departamento de Fitotecnia/UFSM, Santa Maria, RS. E-mail: liliuhlmann@yahoo.com.br \\ ${ }^{4}$ Departamento de Fitotecnia/UFSM, Santa Maria, RS. E-mail: michelrs@live.com \\ ${ }^{5}$ Departamento de Fitotecnia/UFSM, Santa Maria, RS. E-mail: tefa.ds@hotmail.com
}

\section{Palavras-chave:}

Manihot esculenta

efeito estufa

aquecimento global

produção de alimentos

segurança alimentar

\begin{abstract}
R E S U M O
O objetivo nesta revisão é reunir informações da literatura quanto à provável resposta da cultura da mandioca à mudança climática. Na maioria das plantas a taxa de crescimento tende a aumentar com a elevação da concentração de $\mathrm{CO}_{2}$ atmosférico, visto que o $\mathrm{CO}_{2}$ é o substrato para fotossíntese. Porém o aumento da temperatura do ar poderá anular os efeitos benéficos do $\mathrm{CO}_{2}$ na produtividade das culturas, em virtude do encurtamento do ciclo e do aumento da respiração de manutenção. Resultados de experimentos em casa de vegetação, a campo e numéricos, indicam que a resposta da planta de mandioca ao aumento de $\mathrm{CO}_{2}$ é positiva, ou seja, o aumento do $\mathrm{CO}_{2}$ atmosférico resulta em aumento na produtividade de raízes tuberosas de mandioca. $\mathrm{O}$ aumento de temperatura projetada em cenários climáticos futuros não deve, em geral, diminuir a produtividade de raízes tuberosas de mandioca, especialmente na África, onde esta cultura tem papel fundamental na segurança alimentar. Novos estudos devem ser realizados com base no conhecimento atualizado para confirmar estudos anteriores sobre a resposta da cultura da mandioca ao aumento do $\mathrm{CO}_{2}$ e temperatura em regiões ainda pouco estudadas, como o Brasil.
\end{abstract}

Key words:

Manihot esculenta greenhouse effect global warming food production food security

\section{Climate change and its effects on cassava crop}

\begin{abstract}
A B S T R A C T
The objective of this review is to ensemble information from the literature on the response of cassava to climate change. The growth rate of the most plants increases at elevated $\mathrm{CO}_{2}$ because it is the substrate for photosynthesis, however, the increase in temperature may offset the benefits of $\mathrm{CO}_{2}$ on crop productivity due to a shortening of the cycle and increase in respiration of maintenance. Results from greenhouse, field and numerical experiments indicate that the response of cassava crop to elevated $\mathrm{CO}_{2}$ is positive, i.e. the increase in atmospheric $\mathrm{CO}_{2}$ results in increase of storage root yield of cassava. The increase in temperature projected in future climate scenarios in general should not decrease storage root yield of cassava, mainly in Africa, where this crop has an important role on food security. Further studies should be made using the current knowledge in order to confirm previous studies on the response of cassava to elevated $\mathrm{CO}_{2}$ and temperature in regions where few studies have been conducted, like in Brazil.
\end{abstract}

\section{INTRODUÇÃO}

$\mathrm{Na}$ atmosfera, a concentração de dióxido de carbono $\left(\mathrm{CO}_{2}\right)$ vem aumentando desde o início da era industrial, em meados do século XVIII, quando era de aproximadamente $270 \mathrm{ppm}$, alcançando 379 ppm em 2005 (IPCC, 2007) e 397 ppm em 2013 (NOAA, 2013). Em função da contínua emissão para a atmosfera, espera-se que a concentração do $\mathrm{CO}_{2}$ atmosférico duplique (em relação à concentração de 350 ppm) em algum momento deste século (Streck, 2005; O’neill \& Schweizer, 2011). No futuro e caso este aumento da concentração do $\mathrm{CO}_{2}$ continue, poderá ocorrer aumento na temperatura do ar devido ao efeito estufa do $\mathrm{CO}_{2}$ (IPCC, 2007; Maslin \& Austin, 2012) além de aumento no rendimento das culturas, pois o $\mathrm{CO}_{2}$ é o substrato primário na fotossíntese (Streck, 2005).
Atualmente, a segurança alimentar é um dos maiores desafios para a humanidade e para as futuras gerações, pois no cenário atual, pelo menos 800 milhões de pessoas subnutridas e outras 2 bilhões de pessoas com disponibilidade intermitente de alimentos ou em "fome silenciosa" (FAOSTAT, 2012). A mandioca exerce papel fundamental na segurança alimentar nas regiões tropicais por se tratar de uma planta rústica e pouco exigente em fertilidade do solo, adaptada a solos ácidos e a regimes pluviométricos diversos e com elevada tolerância à seca (El-Sharkawy et al., 1989; Alves, 2006) além de se constituir como a terceira maior fonte de alimento, após o arroz e o milho (FAOSTAT, 2012). Mais de 750 milhões de pessoas no mundo, incluindo $45 \%$ de africanos subsaarianos, dependem da mandioca como fonte primária de alimento (Nhassico et al., 2008). Objetivou-se, então, reunir informações da literatura 
sobre a provável resposta da cultura da mandioca à mudança climática.

\section{O Clima Global Passado e Futuro e O Efeito do Aumento da Concentração de $\mathrm{CO}_{2}$ e Temperatura Sobre as Plantas}

Conhecer o clima passado é imprescindível para se entender a variabilidade do clima atual e realizar inferências sobre o clima futuro. Para reconstruir o clima antes de existirem equipamentos de medida dos elementos climáticos (surgiram na metade do século XIX), é necessário usar-se indicadores ou testemunhos de clima, como os cilindros de gelo, corais e aneis de árvores. A reconstrução da temperatura média global dos últimos seis séculos indica um aumento considerável da temperatura a partir de 1900, a qual apresentou correlação positiva com as forçantes concentrações de $\mathrm{CO}_{2}$ e atividade solar (Mann et al., 1998). A reconstrução da temperatura durante os últimos dois milênios indica o século XX com maiores temperaturas sendo a década de 90 e o ano de 1998 os mais quentes (Mann et al., 2008), formando o assim conhecido "Taco de Hoquei" (Mann \& Bradley, 1999).

Várias são as críticas e correções nessas reconstruções do clima passado (McIntyre \& McKitrick, 2003; 2005a; 2005b; Storch et al., 2004; Molion, 2008) e também divergências sobre as causas desse aquecimento, se naturais ou antropogênicas, mas desses trabalhos e do último relatório do IPCC (2007) é evidente que a temperatura global está em ascensão tanto em nível continental como nos oceanos e que a área coberta com geleiras no Planeta, está em declínio. Este aumento de temperatura se estende à América do Sul e ao Brasil e vem ocorrendo assimetricamente em algumas regiões do mundo (Peng et al., 2004; Tao et al., 2006), do Sul do Brasil (Marengo \& Camargo, 2008) e no Rio Grande do Sul (Sansigolo \& Kayano, 2010), com maior aumento na temperatura mínima que na máxima. A forçante climática que está em constante ascensão, é a concentração de gases do efeito estufa, dentre os quais o $\mathrm{CO}_{2}$ é o presente em maior quantidade (IPCC, 2007). A concentração de $\mathrm{CO}_{2}$ da atmosfera terrestre está aumentando a uma taxa de 0,4-0,5\% ano ${ }^{-1}$, o que corresponde a um aumento de 1,0 - 1,8 $\mu \mathrm{mol} \mathrm{CO}$ mol $^{-1}$ ano $^{-1}$ (Streck, 2005). A maior concentração de gases de efeito estufa deverá intensificar a contra-radiação de onda longa (radiação emitida da atmosfera em direção à superfície terrestre), o que altera o balanço de energia e aumenta a temperatura junto à superfície. As projeções são para aumentos de 1,1 a $6,4^{\circ} \mathrm{C}$ na temperatura média global, até o final do século (IPCC, 2007).

Como o $\mathrm{CO}_{2}$ é o substrato primário para a fotossíntese esperase que, com a elevação da concentração desse gás na atmosfera, a taxa de crescimento das plantas aumente (Rosenberg, 1983; Taiz \& Zeiger, 2004). Plantas com metabolismo C3 são mais beneficiadas pelo aumento da concentração de $\mathrm{CO}_{2}$ atmosférico do que plantas com metabolismo $\mathrm{C}_{4}$, pois nas plantas $\mathrm{C}_{3}$ o $\mathrm{CO}_{2}$ compete com o $\mathrm{O}_{2}$ pelo mesmo sítio enzimático e com a maior concentração de $\mathrm{CO}_{2}$ a enzima rubisco, que é a responsável pela carboxilação primária, terá mais afinidade pelo $\mathrm{CO}_{2}$ do que pelo $\mathrm{O}_{2}$, com menor perda por fotorrespiração (Tubiello et al., 2000). O rendimento das culturas pode aumentar em cerca de 30 e $10 \%$ em plantas $\mathrm{C} 3$ e C4, respectivamente, caso dobre a concentração de $\mathrm{CO}_{2}$ (Streck, 2005). Porém um aumento de $1^{\circ} \mathrm{C}$ pode anular os benefícios do $\mathrm{CO}_{2}$ sobre o crescimento e a produtividade das culturas (Streck, 2005) devido ao encurtamento do ciclo (Butterfiel \& Morison, 1992) e ao aumento da respiração de manutenção (Long, 1991; Vu et al., 1997).

Nas culturas tuberosas a fotossíntese, a produtividade de matéria seca total (Fleisher et al., 2008) e de tubérculos (Miglietta et al., 1998) tiveram, em batata, resposta positiva ao enriquecimento de $\mathrm{CO}_{2}$ na atmosfera. No cultivo de primavera, na região de Santa Maria, RS, o aumento simétrico na temperatura de $4{ }^{\circ} \mathrm{C}$ e assimétrico de $5{ }^{\circ} \mathrm{C}$ anula o efeito benéfico do aumento da concentração de $\mathrm{CO}_{2}$ sobre a produtividade de tubérculos de batata (Fagundes et al., 2010). Em beterraba com elevada concentração de $\mathrm{CO}_{2}(550 \mathrm{ppm})$ a produtividade aumentou em $7-16 \%$ e a produtividade de açúcar em 10-15\% (Manderscheid et al., 2010). Em batatadoce utilizando medidas de trocas gasosas, Cen \& Sage (2005) relatam que o enriquecimento da atmosfera com $\mathrm{CO}_{2}$ até a concentração de $560 \mathrm{ppm}$ intracelular promoveu uma taxa fotossintética maior, até a temperatura de $34^{\circ} \mathrm{C}$, decrescendo em temperaturas maiores. Streck (2005) relata maior produtividade de batata, rabanete e batata-doce em atmosfera enriquecida com $\mathrm{CO}_{2}$. Esses e outros trabalhos indicam que as culturas tuberosas, incluindo mandioca, apresentam menor aclimatação ao aumento de $\mathrm{CO}_{2}$ atmosférico que as culturas de grãos, devido à menor limitação de acúmulo de carboidratos nos órgãos de reserva (raízes) que nas partes reprodutivas (grãos) (Kimball et al., 2002; Ainsworth \& Long, 2005; Rosenthal \& Ort, 2012).

\section{Caracterização Geral da Cultura DA MANDiOCA}

A mandioca (Manihot esculenta L. Crantz) é originária da América do Sul, na região sul da Amazônia (Leotard et al., 2009); pertence à família Euphorbiaceae a qual tem, como característica, a presença de látex e glicosídeos cianogênicos; nos séculos XVI e XVII foi amplamente disseminada pelos portugueses para áreas tropicais e subtropicais da África, Ásia e Caribe. Esta cultura tornou-se rapidamente um alimento básico em muitos desses lugares devido sua tolerância às condições adversas de clima e solo (Alves, 2002).

A planta de mandioca é um arbusto perene de hábito indeterminado e comercialmente é propagado vegetativamente através de pedaços do caule denominados manivas (Câmara \& Godoy, 1998). A estrutura morfológica da planta de mandioca pode diferir de acordo com o genótipo, em que alguns apresentam o caule ereto, enquanto outros possuem caule ramificado com duas (dicotômico), três (tricotômico) ou quatro (tetracotômico) hastes (Carvalho \& Fukuda, 2006) denominadas ramificações simpodiais (Matthews \& Hunt, 1994). O número de 
ramificações simpodiais pode ainda depender da sensibilidade do genótipo ao fotoperíodo de modo que fotoperíodos longos estimulam a produção de ramificações simpodiais (Keating et al., 1982).

A parte mais importante da planta é a raiz, rica em fécula, utilizada tanto na alimentação humana e animal quanto como matéria-prima para diversas indústrias (CEPLAC, 2012). Além da alimentação humana a mandioca também é utilizada na alimentação animal, cujas folhas e hastes podem ser fornecidas na forma de silagem, feno, ou mesmo frescas, e como matériaprima para diversos produtos agroindustrializados (Cardoso \& Gameiro, 2006). Devido ainda ao elevado teor de amido nas suas raízes, a mandioca é uma cultura com bom potencial para produção de etanol (Fukuda \& Otsubo, 2003).

Condições ambientais (baixas temperaturas e/ou déficit hídrico prolongado) levam a planta de mandioca a um período dormente ou de repouso (Alves, 2006) caso em que a cultura é geralmente cultivada de forma anual, com plantio no início do período das chuvas nas regiões tropicais e na primavera em regiões subtropicais como o Sul do Brasil. A região preferencial de cultivo é entre as latitudes $15^{\circ} \mathrm{N}$ e $15^{\circ} \mathrm{S}$ mas é possível ser cultivada até $30^{\circ} \mathrm{N}$ e $30^{\circ} \mathrm{S}$ de latitude e em altitudes que variam desde o nível do mar até cerca de $2.300 \mathrm{~m}$. Em virtude da sua boa adaptação em solos ácidos, com baixa fertilidade e a regimes pluviométricos diversos, a mandioca tem sido cultivada em áreas marginais para a agricultura (Alves, 2006). As boas respostas agronômicas obtidas por esta cultura em condições de fertilidade baixa, são devidas à sua eficiência em absorção de nutrientes, sobretudo o fósforo, pela associação de fungos micorrízicos arbusculares nativos (espécie Glomus manihotis), presentes e com alta colonizaçăo nas raízes de mandioca e que se desenvolvem melhor em solos ácidos (Mattos \& Bezerra, 2003).

A planta de mandioca tem, como característica, a tolerância à seca (El-Sharkawy et al., 1989) por possuir um controle estomático altamente eficiente de modo que em situação de déficit hídrico a planta fecha os estômatos diminuindo a condutância estomática e a transpiração, mantendo o potencial hídrico da folha por mais tempo e semelhante ao de uma planta sem déficit hídrico (El-Sharkawy, 2006), o que retarda a desidratação e murchamento das folhas (Taiz \& Zeiger, 2004). A planta manifesta seu potencial produtivo em condições de precipitação anual maior que $600 \mathrm{~mm}$ e sob alta radiação solar (El-Sharkawy, 2004). Em condições de déficit hídrico há uma redução do crescimento da parte aérea sendo o crescimento de folhas e hastes mais prejudicado comparado ao crescimento de raízes. A redução na área foliar auxilia na conservação da água e após o stress a mandioca tende a aumentar a formação de novas folhas com maiores taxas fotossintéticas (El-Sharkawy, 1993; Cayón et al., 1997), com menos matéria seca alocada às hastes (El-Sharkawy \& Cock, 1987; El-Sharkawy et al., 1992). Em condições de déficit hídrico alguns genótipos aumentam o índice de colheita, os quais se tornam até mais produtivos que em condições sem déficit hídrico (Connor et al., 1981; ElSharkawy \& Cadavid, 2002).

\section{Resposta da Mandioca ao Aumento de Temperatura e Concentração DE CO ATMOSFÉrico}

A variabilidade interanual dos elementos meteorológicos afeta a produtividade da mandioca e mudanças no clima poderão trazer importantes consequências sobre a produtividade (EkeOkoro et al., 2009). A brotação das gemas na maniva ébeneficiada em temperaturas do solo em torno de $28-30^{\circ} \mathrm{C}$, porém é paralizada em temperaturas superiores a $37^{\circ} \mathrm{C}$ e inferiores a $17^{\circ} \mathrm{C}$ (El-Shakawy, 2004). Isto indica que um aumento na temperatura global afeta o ciclo de desenvolvimento da planta desde o estabelecimento da cultura, a partir da brotação de gemas, visto que a temperatura do solo está associada à temperatura do ar. Diferentes variedades de mandioca respondem de maneira diferente à temperatura, algumas podendo apresentar maior produtividade sob temperaturas mais elevadas que outras. Por exemplo, comparando quatro variedades de mandioca $(\mathrm{M} \mathrm{Col}$ 22, M Mex 59, M Col 113 e Popayán) cultivadas em três locais na Colômbia com temperaturas médias durante a estação de crescimento de 20,24 e $28{ }^{\circ} \mathrm{C}$, a cultivar Popayán foi a mais produtiva no local com menor temperatura $\left(20^{\circ} \mathrm{C}\right)$ e a menos produtiva nos outros dois locais com maior temperatura (Irikura et al., 1979). Temperaturas foliares na faixa entre $25 \mathrm{e}$ $35^{\circ} \mathrm{C}$ proporcionaram as mais altas taxas fotossintéticas para diversas cultivares de mandioca oriundas de diferentes habitats (El-Sharkawy et al., 1984; El-Sharkawy et al., 1989), sendo máximas entre 30-36 $\mathrm{mmol} \mathrm{CO}_{2} \mathrm{~m}^{-2} \mathrm{~s}^{-1}$ com temperaturas foliares entre $32-37{ }^{\circ} \mathrm{C}$ sob condições de alta radiação solar (El-Sharkawy et al., 1989). Já no estudo de Mahon et al. (1977) as maiores taxas fotossintéticas ocorreram nas temperaturas foliares entre $15-25^{\circ} \mathrm{C}$.

Plantas de mandioca podem manter o crescimento vegetativo e a produção de biomassa sob temperaturas altas $\left(40^{\circ} \mathrm{C}\right) \mathrm{com}$ adequada umidade do solo porém a exportação da sacarose das folhas e a síntese de amido nas raízes são afetadas negativamente. O teor de amido é 3-5\% maior nas raízes em climas amenos e altitude elevada que em planícies mais quentes (Ravi et al., 2008), além do que temperaturas elevadas podem desviar a rota de fotoassimilados para lignificação (Amthor, 2003).

Com relação ao mecanismo fotossintético de fixação de $\mathrm{CO}_{2}$ atmosférico, alguns pesquisadores afirmam que a planta de mandioca possui um ciclo fotossintético intermediário entre plantas $\mathrm{C} 3$ e $\mathrm{C} 4$, pois possui os sistemas enzimáticos favoráveis à fixação de $\mathrm{CO}_{2}$ pelos caminhos $\mathrm{C} 3$ e $\mathrm{C} 4$, mas sem a típica anatomia Kranz de folha C4 (El-Shakawy et al., 1989; El-Shakawy, 2004). No entanto, outros pesquisadores contestam a possibilidade da mandioca ter algum mecanismo fotossintético C4 (Edwards et al., 1990; Calatayud et al., 2002).

$\mathrm{Na}$ literatura foram encontrados quatro trabalhos nos quais foi analisada a resposta da mandioca em diferentes concentrações de $\mathrm{CO}_{2}$ e temperatura a campo ou casa de vegetação; esses experimentos foram conduzidos, respectivamente, no Japão, Austrália, Venezuela e Estados Unidos (Tabela 1). No estudo realizado no Japão por Imai et al. (1984), a resposta da cultura 
da mandioca foi avaliada sob diferentes concentrações de $\mathrm{CO}_{2}$ e temperatura em casa de vegetação, durante 3 meses. Constatou-se acréscimo em todos os parâmetros de crescimento (comprimento da haste, número de folhas, área foliar, número de raízes e acumulação de fitomassa seca de folhas, pecíolos, hastes, raízes e planta inteira) e diminuição da razão parte aérea/ raiz com o aumento da concentração de $\mathrm{CO}_{2}$ de 350 para 700 ppm combinado com o aumento de temperatura de $28 / 21^{\circ} \mathrm{C}$ para $33 / 26^{\circ} \mathrm{C}$ ( $12 \mathrm{~h}$ diurna/ $12 \mathrm{~h}$ noturna). $\mathrm{O}$ aumento da massa seca total da planta sob concentração de 350 para 700 ppm de $\mathrm{CO}_{2}$ foi de $54 \%$ em $28 / 21{ }^{\circ} \mathrm{C}$ e $150 \%$ em $33 / 26^{\circ} \mathrm{C}$, sendo que de raízes foi $234 \%$ em $28 / 21^{\circ} \mathrm{C}$ e $232 \%$ em $33 / 26^{\circ} \mathrm{C}$; observouse ainda que, quanto maior a concentração de $\mathrm{CO}_{2}$, maior também a taxa de assimilação de $\mathrm{CO}_{2}$, apesar da transpiração e da condutância estomática terem diminuído, indicando redução da abertura em atmosfera enriquecida de $\mathrm{CO}_{2}$, mas este fechamento parcial dos estômatos não anulou o efeito do aumento no gradiente de concentração de $\mathrm{CO}_{2}$ entre a atmosfera e a câmara subestomática. Quando as plantas estavam em estágio mais avançado do ciclo de desenvolvimento ocorreu declínio da assimilação de $\mathrm{CO}_{2}$ pelas plantas devido, possivelmente, ao volume limitado de solo ou a redução de nutrientes.

Em trabalho realizado a campo em câmaras de topo aberto na Venezuela, Fernández et al. (2002) avaliaram, durante 8 meses, o efeito do aumento de $\mathrm{CO}_{2}$ em plantas de mandioca sob concentrações de 480 (ambiente) e 680 ppm (elevado). Com um analisador de fotossíntese foliar que mantém uma pequena área da folha sob a concentração de $\mathrm{CO}_{2}$ desejada (cubeta foliar), foram realizadas medidas de trocas gasosas sob concentrações da atmosfera da cubeta de 350 e 700 ppm de $\mathrm{CO}_{2}$ nas câmaras de 480 e $680 \mathrm{ppm}$ de $\mathrm{CO}_{2}$. A taxa fotossintética foi maior nas folhas submetidas à maior concentração de $\mathrm{CO}_{2}$ (700 ppm) que nas submetidas a $350 \mathrm{ppm}$ nos dois ambientes de cultivo. Comparando os dois ambientes de $\mathrm{CO}_{2}$ durante o cultivo a taxa fotossintética das folhas em elevada concentração de $\mathrm{CO}_{2}$ na cubeta (700 ppm) aumentou com o tempo nas plantas sob elevada concentração de $\mathrm{CO}_{2}(680 \mathrm{ppm})$ e diminuiu nas plantas cultivadas em concentração de $\mathrm{CO}_{2}$ ambiente (480 ppm), indicando que uma possível aclimatação do aparato fotossintético pode mudar durante o ciclo de desenvolvimento e que não ocorreu declínio (downregulation) da fotossíntese nas plantas cultivadas em elevado $\mathrm{CO}_{2}(680 \mathrm{ppm})$.

Ainda em Fernández et al. (2002), a condutância estomática foi sempre maior ao longo do ciclo nas folhas submetidas a menor concentração de $\mathrm{CO}_{2}$ na cubeta, em ambos os ambientes de cultivo, principalmente após 150 dias, quando o aumento foi mais evidente no ambiente com concentração de 680 ppm evidenciando o efeito direto da concentração de $\mathrm{CO}_{2}$ no fechamento parcial dos estômatos, inclusive no cultivo em elevado $\mathrm{CO}_{2}$. Em consequência do fechamento parcial dos estômatos a eficiência do uso da água foi maior nas folhas submetidas a $700 \mathrm{ppm}$ nos dois ambientes de cultivo sendo maiores as diferenças entre as folhas submetidas a 350 e 700 ppm em ambiente de elevado $\mathrm{CO}_{2}$, o que indica que plantas em concentração de $\mathrm{CO}_{2}$ elevado aumentam a eficiência de uso da água principalmente pela alta taxa fotossintética, que possibilita maior acúmulo de fitomassa por unidade de água transpirada. A taxa saturante (máxima) de fotossíntese não foi afetada pelo aumento do $\mathrm{CO}_{2}$, mas a eficiência da carboxilação (declividade inicial da relação entre fotossíntese líquida e concentração interna de $\mathrm{CO}_{2}$ ) foi maior na concentração de $350 \mathrm{ppm}$ de $\mathrm{CO}_{2}$. O aumento na eficiência da carboxilação ocorreu em razão da maior atividade da rubisco, já que houve diminuição na concentração de nitrogênio e de rubisco nas folhas, no final do experimento, devido a diluição no tecido ter aumentado a massa seca das folhas. $\mathrm{O}$ teor de amido foi maior

Tabela 1. Condições experimentais e variáveis analisadas em quatro experimentos de aumento da concentração de $\mathrm{CO}_{2}$ sobre a cultura da mandioca

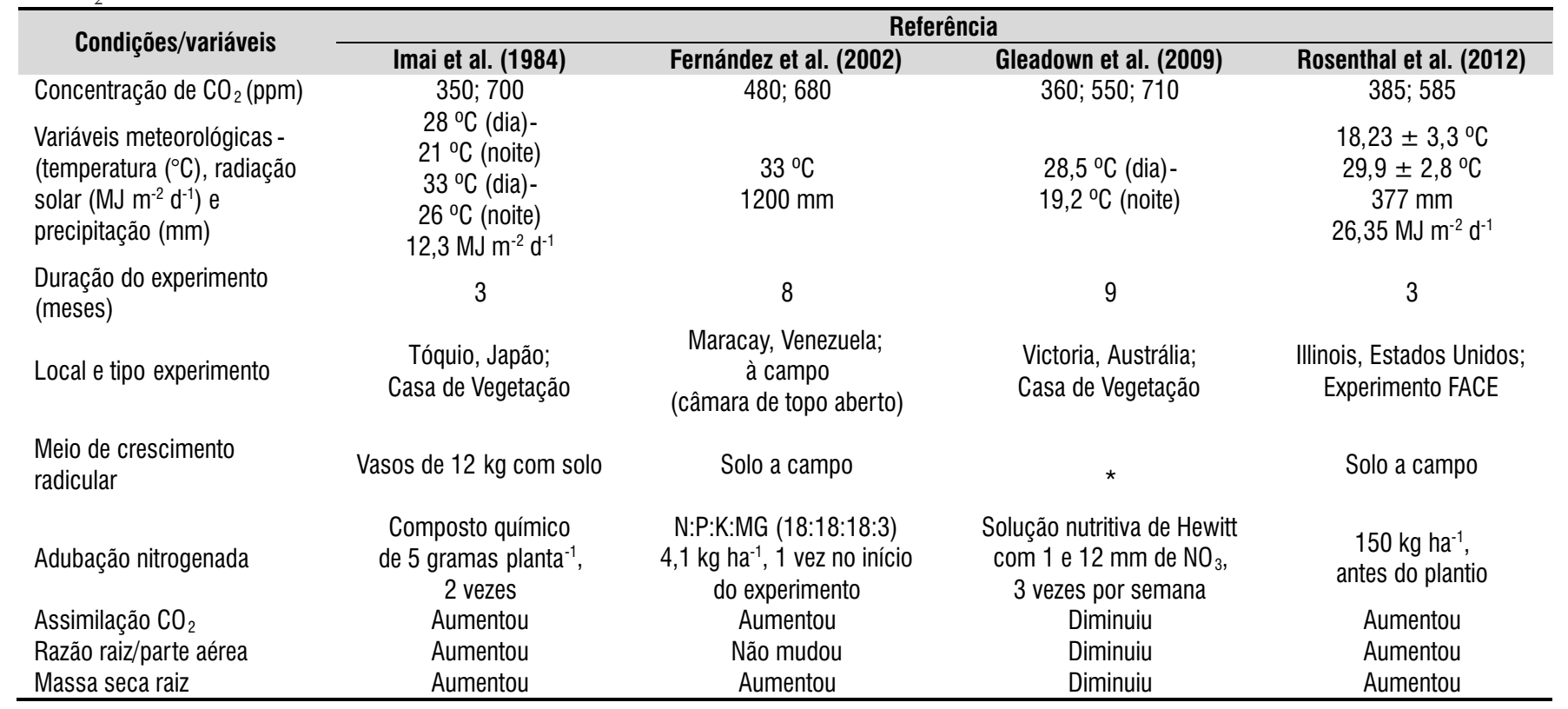

* Não especificado, mas se presume que possa ter sido em vasos 
nas folhas das plantas cultivadas em concentração elevada de $\mathrm{CO}_{2}$ com decréscimo considerável ao longo do ciclo da cultura, o que se deve à translocação do amido para as raízes tuberosas, que se vão tornando fortes drenos ao longo da estação de cultivo Observou-se aumento na massa seca de folhas, hastes, raízes, taxa de crescimento da cultura e índice de área foliar em ambiente com alta $\left[\mathrm{CO}_{2}\right]$, principalmente após 150 dias. A razão raiz/parte aérea, área foliar específica $\left(\mathrm{m}^{2} \mathrm{~g}^{-1}\right)$ e razão de área foliar (área foliar total/massa seca total) não foram afetadas pelo aumento da concentração de $\mathrm{CO}_{2}$, indicando aumento da biomassa da planta sem mudança no padrão de alocação dessa biomassa, diferindo dos resultados de Imai et al. (1984) em que houve redução da razão parte aérea/raiz.

No trabalho realizado na Austrália, plantas de mandioca foram cultivadas em casa de vegetação durante 9 meses sob concentração de 360, 550 e 710 ppm de $\mathrm{CO}_{2}$ com solução nutritiva contendo 1 e $12 \mathrm{~mL}$ de nitrato (baixo e alto $\mathrm{N}$ ) (Gleadow et al., 2009). A produção de biomassa diminuiu linearmente com o aumento do $\mathrm{CO}_{2}$, aproximadamente $1,2 \mathrm{~g}$ para cada aumento de 100 ppm de $\mathrm{CO}_{2}$ nas plantas cultivadas com alto $\mathrm{N}$ e cerca de $0,28 \mathrm{~g}$ por $100 \mathrm{ppm}$ para as plantas com baixo $\mathrm{N}$. Quanto maior a concentração de $\mathrm{CO}_{2}$ menor foi o número de raízes por planta e esta diferença foi maior no tratamento com alto $\mathrm{N}$, o que refletiu em redução de $80 \%$ no índice de colheita das plantas com alto $\mathrm{N}$ e em $710 \mathrm{ppm}$ de $\mathrm{CO}_{2}$ comparado com o das plantas com baixo $\mathrm{N}$ e em 360 ppm de $\mathrm{CO}_{2}$. Apesar da concentração interna de $\mathrm{CO}_{2}(\mathrm{Ci})$ ter aumentado com o aumento da concentração $\mathrm{CO}_{2}$ no ar, a capacidade de assimilação fotossintética e a condutância estomática diminuíram.

Ainda no estudo de Gleadow et al. (2009), as folhas de mandioca acumularam maior teor de nitrogênio total e de glicosídeos cianogênicos quanto maior foi a concentração de $\mathrm{CO}_{2}$ no ambiente e em alto $\mathrm{N}$ mas nas raízes não ocorreu aumento de glicosídeos cianogênicos. Segundo os autores, o aumento de ácido cianídrico $(\mathrm{HCN})$ nas folhas é a hipótese principal para explicar a redução do crescimento da planta de mandioca em atmosfera enriquecida de $\mathrm{CO}_{2}$, pois parte do nitrogênio teria sido alocado para a síntese deste glicosídeo cianogênico ao invés de ter sido alocado para a síntese de Rubisco. Esta hipótese de que a planta aloca recursos nitrogenados para síntese de alcaloides de defesa (que são mecanismos de defesa contra herbívoros generalistas), pode explicar também a redução do tamanho de tubérculos de batata cultivada em atmosfera enriquecida de $\mathrm{CO}_{2}$ (Lawson et al., 2001; Miglietta et al., 1998). Além desta hipótese de mudança de rota metabólica do $\mathrm{N}$ nas folhas de mandioca, a aclimatação ao aumento de $\mathrm{CO}_{2}$ tem sido demonstrada para algumas espécies C3 e esta aclimatação está associada ao acúmulo de carboidratos não estruturais nas folhas (Krapp et al., 1993; Shimon \& Bunce, 2009). Assim conforme Gleadow et al. (2009), a mandioca, ao contrário da maioria das culturas agrícolas (Streck, 2005), não se beneficiaria com o aumento da concentração de $\mathrm{CO}_{2}$ atmosférico.

Os resultados encontrados por Gleadow et al. (2009) são conflitantes com os anteriores, o que ocasionou impacto na comunidade científica já que uma diminuição na produtividade de mandioca em atmosfera enriquecida de $\mathrm{CO}_{2}$ tem impacto potencial negativo elevado na segurança alimentar de países que têm, nesta cultura, uma base muita sólida, como é o caso da África. Motivado por esta controvérsia, um estudo usando a técnica de enriquecimento de $\mathrm{CO}_{2}$ a céu aberto (experimentos FACE), que se aproxima mais da realidade a campo, seria o mais recomendado para o esclarecimento da resposta dessa cultura ao $\mathrm{CO}_{2}$, e também para esclarecer se a concentração de ácido cianídrico nas folhas e raiz aumentaria. Este estudo foi realizado por Rosenthal et al. (2012), nos Estados Unidos e os resultados indicam que, sob elevada concentração de $\mathrm{CO}_{2}(585 \mathrm{ppm})$, a taxa fotossintética média em luz saturante e a fotossíntese total diária do dossel foram, em média, 35 e $29,6 \%$ maior que em concentração de $\mathrm{CO}_{2}$ ambiente (385 ppm), semelhante ao estímulo que ocorre em outras culturas C3 pela fertilização carbônica (Vaccari et al., 2001; Kimball et al., 2002; Ainsworth \& Long, 2005; Ainsworth \& Rogers, 2007; Rosenthal et al., 2011). Os autores ressaltam que um aumento na fotossíntese e na biomassa implica em aumento na eficiência com que a radiação solar interceptada é convertida em biomassa (EUR). A eficiência de uso da água (EUA) foi maior nas plantas em elevada concentração de $\mathrm{CO}_{2}$ no período em que choveu menos, quando a condutância estomática foi bem inferior indicando que sob maior concentração de $\mathrm{CO}_{2}$ as resistências na câmara subestomática aumentam dificultando a perda de água por transpiração. Nos primeiros 2 meses em que a cultura foi imposta à elevada concentração de $\mathrm{CO}_{2}$, houve uma aclimatação fotossintética transitória devido à menor capacidade de carboxilação máxima e ao pouco dreno durante esta fase inicial já que a acumulação de amido nas raízes tuberosas se inicia a partir do segundo mês após o plantio; transcorrido este período inicial, a taxa fotossintética nas plantas em alto $\mathrm{CO}_{2}$ retornou a valores similares aos das plantas culticadas em $\mathrm{CO}_{2}$ ambiente, resultando em copas mais altas $(\mathrm{cm})$ e de maior tamanho $\left(\mathrm{m}^{3}\right)$, maior número de folhas e sem apresentar aceleração na senescência das folhas sob elevada concentração de $\mathrm{CO}_{2}$, como já foi encontrado em outros tubérculos (Miglietta et al., 1998; Manderscheid et al., 2010). Assim, as plantas cultivadas em ambiente com elevado $\mathrm{CO}_{2}$ tiveram um Índice de Área Foliar maior, menor área foliar específica e produção de massa seca $30 \%$ maior em parte aérea e $105 \%$ maior em raízes tuberosas, consequentemente com aumento no índice de colheita. Assim como os resultados de Imai et al. (1984) e Fernández et al. (2002), o aumento na produção de parte aérea e raízes de mandioca é superior ao das encontradas para outras culturas tuberosas como batata (21\% maior) (Miglietta et al., 1998) e beterraba (17\% maior) (Manderscheid et al., 2010) em semelhante concentração de $\mathrm{CO}_{2}$. Comparada a outras culturas, esta maior vantagem da mandioca se deve à alta taxa fotossintética combinada ao maior dossel foliar, visto que proporcionam uma capacidade maior de produção de biomassa e também em razão desta cultura possuir ótima temperatura do ar para seu crescimento e desenvolvimento superiores aos de outras culturas tuberosas, característica de plantas adaptadas a ambientes quentes (tropicais). O conteúdo de nitrogênio e 
de ácido cianídrico nas folhas completamente expandidas foi menor em ambiente com elevada concentração de $\mathrm{CO}_{2}$ devido à diluição do nitrogênio na fitomassa, conforme já relatado para espécies de plantas não leguminosas cultivadas em concentração de $\mathrm{CO}_{2}$ elevado (Leakey et al., 2009). Com base nesses resultados experimentais é mais provável que a cultura da mandioca seja beneficiada pelo aumento da concentração de $\mathrm{CO}_{2}$ atmosférico já que os resultados de aumento da concentração de ácido cianídrico nas folhas e diminuição da produção de raízes encontradas em Gleadown et al. (2009), podem ter sido devidos a deficiências de relação dos nutrientes durante o experimento e colonização micorrízica e estão sendo explorados por seus autores (Rosenthal et al., 2012).

Experimentos numéricos simulando a produtividade da mandioca foram realizados para algumas regiões do mundo em cenários climáticos futuros, com mudanças na temperatura e na precipitação (Lobell et al., 2008; Schlenker \& Lobell, 2010; Jarvis et al., 2012) e também na concentração de $\mathrm{CO}_{2}$ (Liu et al., 2008). Com o uso de um modelo agrometeorológico estatístico com base em um histórico de colheitas das culturas e de 20 modelos climáticos de circulação geral (GCMs) da geração CMIP3 que foram usados no quarto relatório do IPCC (2007), Lobell et al. (2008) realizaram um trabalho priorizando o estudo de culturas importantes para a segurança alimentar em diferentes regiões do mundo simulando a produção dessas culturas em cenários climáticos para 2030. Com a simulação de aumento de temperatura e diminuição da precipitação para o Brasil, a mandioca apresentou diminuição da produtividade de cerca de $5 \%$. Com o foco na região que concentra o maior problema de desnutrição no mundo, a África Subsaariana, Schlenker \& Lobell (2010) avaliaram a produtividade de mandioca também com um modelo agrometeorológico e em cenários de alterações nas temperaturas mínimas e máximas, além de mudanças relativas de precipitação, obtidas por 16 modelos de mudança climática no cenário $\mathrm{A} 1 \mathrm{~b}$, cenário de emissão de $\mathrm{CO}_{2}$ intermediária do IPCC (2007) para meados do século (2046-2065) e encontraram diminuição de cerca de $8 \%$ na produtividade de mandioca, diminuição menor que para as demais culturas estudadas como milho (-22\%), sorgo $(-17 \%)$, milheto $(-17 \%)$ e amendoim $(-18 \%)$. Liu et al. (2008) avaliaram a produtividade de seis culturas principais na região Subsaariana da África com o modelo baseado em processos denominado GEPIC para a simulação das culturas forçada por cenários climáticos futuros regionalizados (downscaling) a partir do modelo global HadCM3 para os cenários A1FI, A2, B1 e B2 do IPCC (2007), no período 2030-39. Em todos os cenários o impacto na mudança da produtividade de mandioca foi desprezível. Com o objetivo de fazer uma atualização a um tema já levantado por Kamukondiwa (1996) sobre o potencial adaptativo da cultura da mandioca à mudança climática na África, Jarvis et al. (2012) quantificaram este potencial usando o modelo EcoCrop, um modelo mecanístico simples, projetado para operar em escala mensal de tempo e capaz de analisar a geografia de aptidão agrícola com relação às condições climáticas e projeções do cenário de emissões SRES
A1B (IPCC 2007) no período (2020-2049) de 24 diferentes modelos climáticos globais (GCMs) com um downscaling usando um modelo climático regional (RCM). Este trabalho indicou impactos das mudanças climáticas sobre a produção de mandioca que variaram de $-3,7 \%$ a $17,5 \%$ ao longo do continente africano. Em outro estudo numérico, na Tailândia, sobre o impacto da mudança climática na cultura da mandioca considerando $1 \mathrm{x}, 1,5 \mathrm{x}$ e $2 \mathrm{x}$ a concentração de $\mathrm{CO}_{2}$ atual, houve decréscimo na produtividade em anos normais e secos, e um pequeno aumento em anos chuvosos (Chinvanno, 2004).

No Brasil, de acordo com Assad \& Pinto (2008), a cultura da mandioca terá um aumento da área de plantio com baixo risco, principalmente na região Sul, devido à diminuição de locais sujeitos a geadas, e na Amazônia, em decorrência da diminuição dos excedentes hídricos, porém com graves perdas no Nordeste pois o aumento de temperatura deve levar a uma expansão das áreas de alto risco de produção de mandioca no Semiárido e no Agreste nordestino, onde a mandioca é mais significativa para a segurança alimentar.

Os resultados dos experimentos numéricos indicam que a resposta da cultura da mandioca à mudança climática varia com a região do globo e com a variabilidade interanual de precipitação. Para a África, continente em que a mandioca tem papel fundamental na segurança alimentar, os resultados indicam maior possibilidade da produtividade de mandioca não decrescer na maioria dos estudos, o que é animador na medida em que as comunidades e nações deste continente são, em geral, altamente vulneráveis. $\mathrm{O}$ último experimento FACE com a cultura da mandioca (Rosenthal et al., 2012), aumentou o embasamento fisiológico sobre a resposta dessa cultura ao aumento de $\mathrm{CO}_{2}$, o que possibilita novos estudos com modelos numéricos incorporando este recente conhecimento, de modo a simular o impacto de cenários climáticos futuros no crescimento, desenvolvimento e produtividade desta cultura, com mais segurança.

Por fim e apesar do avanço conseguido nos últimos anos com os experimentos acima relatados, ainda são necessários mais estudos sobre a resposta da mandioca em cenários climáticos futuros, como o que está em andamento na região Sul do Brasil, a partir de experimentos numéricos com um modelo ecofisiológico de mandioca calibrado para o Estado do Rio Grande do Sul por Gabriel (2013). Também o grupo de modeladores do CIAT (Centro Internacional de Agricultura Tropical), fisiologistas de mandioca e os modeladores responsáveis pelo módulo de mandioca no Sistema de Apoio à Decisão para Transferência de Agrotecnologia (DSSAT) estão preparando este modelo para, futuramente, ser usado em cenários de mudança climática, com a ajuda também do grupo de modelagem de mandioca APSIM (Simulador de Sistemas de Produção Agrícola) desenvolvido pela Unidade de Pesquisa Agropecuária em Sistemas de Produção na Austrália e pelo grupo de modelagem de mandioca "MunThaiDSS: A Decision Support System for Cassava Production" (Departamento de Agricultura, Centro de Pesquisas de Culturas Agrícolas Khon Kaen, Tailândia) (Hoogenboom et al., 2012). 


\section{Conclusões}

1. O aumento do $\mathrm{CO}_{2}$ atmosférico resulta em aumento na produtividade de raízes tuberosas de mandioca.

2. O aumento de temperatura projetada em cenários climáticos futuros não deve, em geral, diminuir a produtividade de raízes tuberosas de mandioca especialmente na África, onde esta cultura tem papel fundamental na segurança alimentar.

3. Novos estudos devem ser realizados com base no conhecimento atualizado para confirmar estudos anteriores sobre a resposta da cultura da mandioca ao aumento do $\mathrm{CO}_{2} \mathrm{e}$ temperatura e em regiões ainda pouco estudadas, como o Brasil.

\section{Literatura Citada}

Ainsworth, E. A.; Long, S. P. What have we learned from 15 years of Free-Air $\mathrm{CO}_{2}$ Enrichment (FACE)? A meta-analytic review of the responses of photosynthesis, canopy properties and plant production to rising $\mathrm{CO}_{2}$. New Phytologist, v.165, p.351-371, 2005.

Ainsworth, E. A.; Rogers, A. The response of photosynthesis and stomatal conductance to rising $\left[\mathrm{CO}_{2}\right]$ : Mechanisms and environmental interactions. Plant Cell and Environment, v.30, p.258-270, 2007.

Alves, A. A. C. Cassava botany and physiology. In: Hillocks, R. J.; Thresh, J. M.; Bellotti, A. C. Cassava: Biology, production and utilization. Oxon: CABI Publishing, 2002, p.67-89.

Alves, A. A. C. Fisiologia da mandioca. In: Aspectos socioeconômicos e agronômicos da mandioca. Cruz das Almas: Embrapa Mandioca e Fruticultura Tropical, 2006. Cap.7, p.138-169.

Amthor, J. S. Efficiency of lignin biosynthesis: a quantitative analysis. Annals of Botany, v.91, p.673-695, 2003.

Assad, E. D.; Pinto, H. S. Aquecimento global e a nova geografia da produção agrícola no Brasil. São Paulo: EMBRAPA, 2008. 84p.

Butterfield, R. E.; Morison, J. I. L. Modeling the impact of climate warming on winter cereal development. Agricultural and Forest Meteorology, v.62, p.241-261, 1992.

Câmara, G. M. S.; Godoy, O. P. I. Desempenho vegetativo e produtivo de cultivares de mandioca (Manihot esculenta Crantz) a partir de manivas com diferentes diâmetros. Scientia Agricola, v.55, p. 326-333, 1998.

Cardoso, C. E. L.; Gameiro, A. H. Caracterização da cadeia agroindustrial. In: Embrapa Mandioca e Fruticultura Tropical. Aspectos socioeconômicos e agronômicos da mandioca. Cruz das Almas: Embrapa Mandioca e Fruticultura Tropical, 2006. cap.1, p.20-40.

Carvalho, J. E.; Fukuda, W. M. G. Estrutura da planta e morfologia. In: EMBRAPA Mandioca e Fruticultura Tropical. Aspectos socioeconômicos e agronômicos da mandioca. Cruz das Almas: Embrapa Mandioca e Fruticultura Tropical, 2006. Cap.6, p.126-137.
Calatayud, P. A.; Barón, C. H.; Velásquez, H.; Arroyave, J. V.; Lamaze, T. Wild manihot species do not possess $\mathrm{C} 4$ photosynthesis. Annals of Botany, v.89, p.125-127, 2002.

Cayón, M. G.; El-Sharkawy, M. A.; Cadavid, L. F. Leaf gas exchange of cassava as affected by quality of planting material and water stress. Photosynthetica, v.34, p.409-418, 1997.

Cen, Y. P.; Sage, R. F. The regulation of Rubisco activity in response to variation in temperature and atmospheric $\mathrm{CO}_{2}$ partial pressure in sweet potato. Plant Physiology, v.139, p.979-990, 2005.

CEPLAC - Comissão Executiva do Plano da Lavoura Cacaueira. Mandioca. Distrito Federal: CEPLAC. http://www.ceplac. gov.br/radar/Mandioca.htm 15 Mar. 2012.

Chinvanno, S. Building capacity of mekong river countries to assess impacts from climate change - Case study approach on assessment of community vulnerability and adaptation to impact of climate change on water resources and food production. Final Report for APN CAPaBLE Project, 2004. http://cc.start.or.th/climateChange/Document/Doc_eng_3. pdf. 5 Jun. 2011.

Connor, D. J.; Cock, J. H.; Parra, G. E. Response of cassava to water shortage. I. Growth and yield. Field Crops Research, v.4, p.181-200, 1981.

Edwards, G. E.; Sheta, E. ; Moore, B.; Dai, Z. ; Franceschi, V. R.; Cheng, S. H.; Lin, C. H.; Ku, M. S. B. Photosynthetic characteristics of cassava (Manihot esculenta Crantz), a C3 species with Chlorenchymatous bundle sheath cells. Plant Cell Physiology, v.31, p.1199-1206, 1990.

Eke-Okoro, O. N.; Njoku, D. N.; Madu, A.; Ezulike, T. O. Impact of global warming and crops factors on the growth and productivity of four cassava (Manihot esculenta Crantz) cultivars in Nigeria. Scientific Research and Essays, v.4, p.955-960, 2009.

El-Sharkawy, M. A. Drought-tolerant cassava for Africa, Asia and Latin America: breeding projects work to stabilize productivity without increasing pressures on limited natural resources. BioScience, v.43, p.441-451, 1993.

El-Sharkawy, M. A. Cassava biology and physiology. Plant Molecular Biology, v.56, p.481-501, 2004.

El-Sharkawy, M. A. International research on cassava photosynthesis, productivity, eco-physiology, and responses to environmental stresses in the tropics. Photosynthetica, v.44, p.481-512, 2006.

El-Sharkawy, M. A.; Cadavid, L. F. Response of cassava to prolonged water stress imposed at different stages of growth. Experimental Agriculture, v.38, p.333-350, 2002.

El-Sharkawy, M. A.; Cock, J. H. Response of cassava to water stress. Plant and Soil, v.100, p.345-360, 1987.

El-Sharkawy, M. A.; Cock, J. H.; Held, A. A. Photosynthetic response of cassava cultivars (Manihot esculenta Crantz) from different habitats to temperature. Photosynthesis Research, v.5, p.243-250, 1984. 
El-Sharkawy, M. A.; Cock, J. H. Porto, M. C. M. Características fotossintéticas da mandioca (Manihot esculenta Crantz). Revista Brasileira de Fisiologia Vegetal, v.1, p.143-154, 1989.

El-Sharkawy, M. A.; Hernandez, A. d. P.; Hershey, C. Yield stability of cassava during prolonged mid-season water stress. Experimental Agriculture, v.28, p.165-174, 1992.

Fagundes, J. D.; Paula, G. M. de.; Lago, I. ; Streck, N. A.; Bisognin, D. A. Aquecimento global: efeitos no crescimento, no desenvolvimento e na produtividade de batata. Ciência Rural, v.40, p.1464-1472, 2010.

FAOSTAT - Food and Agriculture Organization of the United Nations. Production, crops. http://faostat.fao.org/site/339/ default.aspx. 29 Mar. 2011.

Fernández, M. D.; Tezara, D.; Rengifo, E.; Herrera, A. Lack of down-regulation of photosynthesis in a tropical root crop, cassava grown under an elevated $\mathrm{CO}_{2}$ concentration. Functional Plant Biology, v.29, p.805-814, 2002.

Fleisher, D. H.; Timlin, D. J.; Reddy, V. R. Elevated carbon dioxide and water stress effects on potato canopy gas exchange, water use, and production. Agricultural and Forest Meteorology, v.148, p.1109-1122, 2008.

Fukuda, C.; Otsubo, A. A. Cultivo da mandioca na região centro sul do Brasil. Embrapa Mandioca e Fruticultura: Sistemas de Produção. 2003. http://sistemasdeproducao.cnptia.embrapa. br/FontesHTML/Mandioca/mandioca_centrosul/index. htm. 5 Abr. 2011.

Gabriel, L.F. Simulação da produtividade de mandioca para o estado do Rio Grande do Sul. Santa Maria: UFSM, 2013. 92p. Dissertação Mestrado

Gleadow, R. M.; Evans, J. R.; McCaffery, S.; Cavagnaro, T. R. Growth and nutritive value of cassava (Manihot esculenta Cranz.) are reduced when grown in elevated $\mathrm{CO}_{2}$. Plant Biology, v.11, p.76-82, 2009.

Hoogenboom, G.; Hunt, T.; Jarvis, A.; Cock, J.; Fisher, M.; Ramirez, J.; Moreno, P.; Barrios, C. News Bulletin on the Cassava modeling group: Rethinking a cassava crop model. Cali: Centro Internacional de Agricultura Tropical (CIAT), 2012. 12p.

Imai, K.; Coleman, D. F.; Yanagisawa, T. Elevated atmospheric partial pressure of carbondioxide and dry matter production of cassava (Manihot esculenta Crantz.). Japan Journal Crop Science, v.53, p.479-485, 1984.

IPCC - Intergovernmental Panel on Climate Change. Climate change 2007: The physical science basis. Contribution of Working Group I to the Fourth Assessment Report of the Intergovernmental Panel on Climate Change [Solomon, $\mathrm{S}$. D.; Qin, M.; Manning, Z.; Chen, M.; Marquis, K. B.; Averyt, M.; Tignor and H. L. Miller (ed.)]. Cambridge: University Press, United Kingdom and New York, 2007. 996p.

Irikura, Y.; Cock, J. H.; Kawano, K. The physiological basis of genotype temperature interactions in cassava. Field Crops Research, v.2, p.227-239, 1979.

Jarvis, A.; Ramirez-Villegas, J.; Campo, B. V. H.; NavarroRacines, C. Is Cassava the Answer to African Climate Change Adaptation? Tropical Plant Biology, v.5, p.9-29, 2012.
Kamukondiwa, W. Alternative food crops to adapt to potential climatic change in southern Africa. Climate Research, v.6, p.153-155, 1996.

Keating, B. A.; Evenson, J. P.; Fukai, S. Environmental effects in growth and development of cassava (Manihot esculenta Crantz). I. Crop development. Field Crops Research, v.5, p.271-281, 1982.

Kimball B. A.; Kobayashi, K.; Bindi, M. Responses of agricultural crops to free-air $\mathrm{CO}_{2}$ enrichment. Advances in Agronomy, v.77, p.293-368, 2002.

Krapp A.; Hoffman B.; Schafer C.; Stitt M. Regulation of the expression of $\mathrm{rbcS}$ and other photosynthetic genes by carbohydrates: a mechanism for the 'sink regulation' of photosynthesis? The Plant Journal, v.3, p.817-828, 1993.

Lawson, T.; Craigon, J.; Black, C. R.; Colls, J. J.; Tulloch, A.-M.; Landon, G. Effects of elevated carbon dioxide and ozone on the growth and yield of potatoes (Solanum tuberosum) grown in open-top chambers. Environmental Pollution, v.111, p.479-491, 2001.

Leakey, A. D. B.; Ainsworth, E. A.; Bernacchi, C. J.; Rogers, A.; Long, S. P.; Ort, D. R. Elevated $\mathrm{CO}_{2}$ effects on plant carbon, nitrogen, and water relations: six important lessons from FACE. Oxford Journals, v.60, p.2859-2876, 2009.

Leotard, G.; Duputié, A.; Kjellberg, F.; Douzery, E. J. P.; Debain, C.; Granville, J. J. de.; McKey, D. Phylogeography and the origin of cassava: New insights from the northern rim of the Amazonian basin. Molecular Phylogenetics and Evolution, v.53, p.329-334, 2009.

Liu, J.; Fritz, S.; Wesenbeeck, C. F. A.; Fuchs, M.; You, L.; Obersteiner, M.; Yang, H. A spatially explicit assessment of current and future hotspots of hunger in sub-Saharan Africa in the context of global change. Global and Planetary Change, v.64, p.222-235, 2008.

Lobell, D. B.; Burke, M. B.; Tebaldi, C. ; Matrandrea, M. D.; Falcon, W. P.; Naylor, L. R. Prioritizing climate change adaptation needs for food security in 2030. Science, v.319, p.607-610, 2008.

Long, S. P. Modification of the response of photosynthetic productivity to rising temperature by atmospheric $\mathrm{CO}_{2}$ concentrations: Has its importance been underestimated? Plant, Cell and Environment, v.14, p.729-739, 1991.

Mahon, J. D.; Lowe, S. B.; Hunt, L. A. Environmental effects on photosynthesis and transpiration in attached leaves of cassava (Manihot esculenta Crantz). Photosynthetica, v.11, p.121-130, 1977.

Mann, M. E.; Bradley, R. S. Northern hemisphere temperatures during the past millennium: Inferences, uncertainties, and limitations. Geophysical Research Letters, v.26, p.759-762, 1999.

Mann, M. E.; Bradley, R. S.; Hughes, M. K. Global-scale temperature patterns and climate forcing over the past six centuries. Nature, v.392, p.779-787, 1998. 
Mann, M. E.; Zhang, Z.; Hughes, M. K.; Bradley, R. S.; Miller, S. K.; Rutherford, S.; Ni, F. Proxy-based reconstructions of hemispheric and global surface temperature variations over the past two millennia. Proceedings of the National Academy of Sciences of the United States of America, v.105, p.13252-13257, 2008.

Mandercheid, R.; Pacholsky, A.; Weigel, H. J. Effect of free air carbon dioxide enrichment combined with two nitrogen levels on growth, yield and yield quality of sugar beet: Evidence for a sink limitation of beet growth under elevated $\mathrm{CO}_{2}$. European Journal of Agronomy, v.32, p.228-239, 2010.

Marengo, J. A.; Camargo, C. C. Surface air temperature trends in Southern Brazil for 1960-2002. International Journal of Climatology, v.28, p.893-904, 2008.

Maslin, M.; Austin, P. Climate models at their limit ? Nature, v.486, p.183-184, 2012.

Matthews, R. B.; Hunt, L. A. GUMCAS: a model describing the growth of cassava (Manihot esculenta L. Crantz. Field Crops Research, v.36, p.69-84, 1994.

Mattos, P. L. P. de.; Bezerra, V. S. Cultivo da mandioca para o Estado do Amapá. EMBRAPA Mandioca e Fruticultura: Sistemas de Produção, 2003. http://sistemasdeproducao. cnptia.embrapa.br/FontesHTML/Mandioca/mandioca_ amapa/sementes.htm 19 Mar. 2012

McIntyre, S.; McKitrick, R. Corrections to the Mann et. al. (1998) proxy data base and northern hemispheric average temperature series. Energy \& Environment, v.14, p.751-771, 2003.

McIntyre, S.; McKitrick, R. The M\&M Critique of the MBH98 Northern Hemisphere climate index: update and implications. Energy \& Environment, v.16, p.69-100, 2005a.

McIntyre, S.; McKitrick, R. Hockey sticks, principal components, and spurious significance. Geophysical Research Letters, v.32, L03710, 2005b.

Miglietta, F.; Magliulo, V.; Bindi, M.; Cerio, L.; Vaccari, F. P.; Loduca, V.; Peressotti, A. Free Air $\mathrm{CO}_{2}$ enrichment of potato (Solanum tuberosum L.): Development, growth and yield. Global Change Biology, v.4, p.163-172, 1998.

Molion, L. C. B. Aquecimento global: uma visão crítica. Revista Brasileira de Climatologia, v.3-4, p.7-24, 2008.

Nhassico, D.; Muquingue, H.; Cliff, J.; Cumbana, A.; Bradbury, J. H. Rising African cassava production, diseases due to high cyanide intake and control measures. Journal of the Science of Food and Agriculture, v.88, p.2043-2049, 2008.

NOAA - National Oceanic and Atmospheric Administration. Up-to-date weekly average $\mathrm{CO}_{2}$ at Mauna Loa. http://www. esrl.noaa.gov/gmd/ccgg/trends/weekly.html. 2 Mar. 2013.

O'Neill, B. C.; Schweizer, V. Mapping the road ahead. Nature Climate Change, v.1, p.352-353, 2011.

Peng, S.; Huang, J.; Sheehy, J. E.; Laza, R. C.; Visperas, R. M.; Zhong, X.; Centeno, G. S.; Khush, G. S.; Cassman, K. G. Rice yields decline with higher night temperature from global warming. National Academy of Sciences of the USA, v.101, p.9971-9975, 2004.
Ravi, V.; Ravindran, C. S.; Ramesh, V. The impact of climate change on photosynthesis and productivity of cassava and sweet potato: Effect of rise in temperature, $\mathrm{CO}_{2}$ and UV-B Radiation: an Overview. Journal of Root Crops, v.34, p.95107, 2008.

Rosenberg, N. Microclimate: The biological environment. New York: John Wiley \& Sons, 1983. 495p.

Rosenthal D. M.; Locke, A. M.; Khozai, M.; Raines, C. A.; Long, S. P.; Ort, D. R. Overexpressing the $\mathrm{C} 3$ photosynthesis cycle enzyme sedoheptulose-1-7 bisphosphatase improves photosynthetic carbon gain and yield under fully open air $\mathrm{CO} 2$ fumigation (FACE). BMC Plant Biology, v.11, p.123-134, 2011.

Rosenthal, D. M.; Ort, D. R. Examining cassava’s potential to enhance food security under climate change. Tropical Plant Biology, v.5, p.30-38, 2012.

Rosenthal, D. M.; Slattery, R. A.; Miller, R. E.; Grennan, A. K.; Cavagnaro, T. R.; Fauquet, C. M.; Gleadow, R. M.; Ort, D. R. Cassava about-FACE: Greater than expected yield stimulation of cassava (Manihot esculenta) by future $\mathrm{CO}_{2}$ levels. Global Change Biology, v.18, p.2661-2675, 2012.

Sansigolo, C. A.; Kayano, M. T. Trends of seasonal maximum and minimum temperatures and precipitation in Southern Brazil for the 1913-2006 period. Theoretical and Applied Climatology, v.101, p.209-216, 2010.

Schlenker. W.; Lobell, D. B. Robust negative impacts of climate change on African agriculture. Environmental Research Letters, v.5, p.1-8, 2010.

Shimon, H.; Bunce, J. A. Acclimation of nitrogen uptake capacity of rice to elevated atmospheric $\mathrm{CO}_{2}$ concentration. Annals of Botany, v.103, p.87-94, 2009.

Storch, H. von; Zorita, E.; Jones, J. N.; Dimitriev, Y.; GonzálesRouco, F.; Tett, S. F. B. Reconstructing Past Climate from Noisy Data. Science, v.306, p.679-682, 2004.

Streck, N. A. Climate change and agroecosystems: the effect of elevated $\mathrm{CO}_{2}$ and temperature on crop growth, development, and yield. Ciência Rural, v.35, p.730-740, 2005.

Taiz, L.; Zeiger, E. Fisiologia vegetal. Porto Alegre: Artemed, 3.ed. 2004. 719p.

Tao, F.; Yokozawa, M.; Xu, Y.; Hayashy, Y.; Zhang, Z; Climate changes and trends in phenology and yields of field crops in China, 1981-2000. Agricultural and Forest Meteorology, v.138, p.82-92, 2006.

Tubiello, F. N.; Donatelli, M.; Rosenzweig, C.; Stockle, C. O. Effects of climate change and elevated $\mathrm{CO}_{2}$ on cropping systems: Model predictions at two Italian locations. European Journal of Agronomy, v.13, p.179-189, 2000.

Vaccari, F. P.; Miglietta, F.; Magliulo, V.; Giuntoli, A.; Cerio, L.; Bindi, M. Free air $\mathrm{CO}_{2}$ enrichment of potato Solanum tuberosum L.: photosynthetic capacity of leaves. Italian Journal of Agronomy, v.5, p.3-10, 2001.

Vu, J. C. V.; Allen Jr, L. H.; Boote, K. J.; Bowes, G. Effects of elevated $\mathrm{CO}_{2}$ and temperature on photosynthesis and Rubisco in rice and soybean. Plant, Cell and Environment, v.20, p.68-76, 1997. 